\title{
Guidelines Towards the Facilitation of Interactive Online Learning Programmes in Higher Education
}

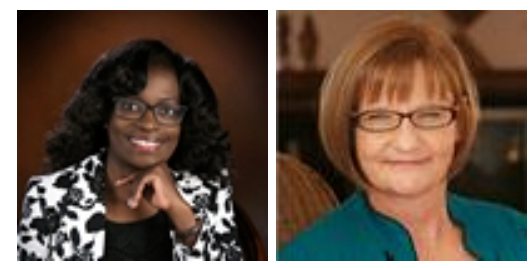

Lydia Mbati and Ansie Minnaar

University of South Africa

\begin{abstract}
The creation of online platforms that establish new learning environments has led to the proliferation of institutions offering online learning programmes. However, the use of technologies for teaching and learning requires sound content specialization, as well as grounding in pedagogy. While gains made by constructivism and observational learning are well documented, research addressing online practices that best encourage constructivist and observational learning in Open and Distance Learning (ODL) contexts is limited.

Using a phenomenological methodological approach, this research explored the lived experiences of online learning programme facilitators at an Open and Distance Learning higher education institution. The findings of this research study revealed that facilitators did not use constructivist and observational learning pedagogies to a large extent in their interaction with students. It is concluded that during the curriculum planning phase, facilitators should decide on methods and media to arouse the students' attention and stimulating constructivist and observational learning amongst students during online courses. This also implies a more reasonable facilitator-student ratio because large numbers of students per facilitator proves not feasible in online learning. The paper concludes by providing guidelines for the facilitation of interactive online learning programmes.
\end{abstract}

Keywords: Interactive online learning; constructivism; observational learning 


\section{Introduction}

There has been a proliferation of online learning courses offered by universities, and many other educational providers are in the process of implementing such courses. This is a result of the creation of online platforms that establish new learning environments offering multidimensional learning possibilities (Chang \& Tung, 2008:71-83; Tuquero, 2011:157-179). The use of technology for learning purposes requires content specialization as well as grounding in pedagogy (Koehler \& Mishra, 2009:60-70). Models and guidelines exist for the facilitation of online courses in general (Ally, 2004; Moule, 2007: 37-50) and others for online learning that results in constructivist learning (Salmon, 2011). While models and guidelines exist, the guidelines are based on aspects of constructivist learning in general, models and guidelines for online learning that stimulate constructivist as well as observational learning are lacking. This study sought to provide guidelines for online learning based on constructivism (Baviskar, Hartle \& Whitney, 2009: 542-550) and observational learning (Bandura, 2001: 265-299). Online learning programmes ought to facilitate learning through social interactions. Feelings of social disconnectedness and lack of familiar teacher immediacy as well as the lack of interpersonal interactions have led to higher than average attrition rates in online learning programmes (Slagter van Tryon \& Bishop, 2009:291).

The need to align online practices to sound pedagogical approaches has been alluded to in literature (Baggaley, 2014:133-134; Vianna (2009) in Green et al (2010:257-273)) with criticisms for some pedagogical groundings for online courses (Clara \& Barbera, 2013:129-136). Behaviourist, cognitivist and constructivist learning can serve as taxonomy for online learning (Ally 2004:6-31). The purpose of the research on which this article is based, was to provide guidelines for the facilitation of interactive online learning that stimulate both constructivist learning (Baviskar, Hartle \& Whitney, 2009: 542-550) and observational learning (Bandura, 2001: 265-299) on the part of students. The guidelines emerged from a phenomenological exploration into the lived experiences of online learning facilitators regarding constructivist and observational learning based facilitation practices. The research took place in The University of South Africa (Unisa), an Open and Distance Learning (ODL) institution in South Africa, which is in the process of initiating online learning programmes.

\section{Literature Review}

So (2012:143-158) investigated the learning outcomes of 25 student teachers in an online videobased learning community. Using a qualitative research approach, the study revealed that the student teachers benefitted from the opportunities for peer interaction and self-reflection. Peer collaboration and reflective skills were promoted through the viewing of video clips (Zhang et al, 2011; Harford \& MacRuairc, 2008 in So, 2012:143). In furthering So's (2012:143-158) and others

This work is licensed under a $\underline{\text { Creative Commons Attribution } 4.0 \text { International License. }}$ 
findings (Baggaley, 2014:133-134; Vianna (2009) in Green et al (2010:257-273)), (Blocher, 2005: 269-278 and (Clara \& Barbera, 2013:129-136), the current guidelines for online learning are based on practice as well as online media.

Guidelines for the design of a framework for cooperative learning to enhance learner interactivity in online learning environments are presented by Blocher (2005: 269-278). The guidelines are based on collaborative learning activity based on active, collaborative and constructivist approaches that are supported through the development of a strong sense of community, a distributed learning community. The theoretical framework in which the study was grounded is distributed learning that distributes the constructing of knowledge throughout the community of learners (Blocher, 2005: 269-278). The paper provides insights into designing online distributed learning based on constructivist learning and a "rotating" J igsaw approach. Constructivism as a learning theory consists of cognitive constructivism and social constructivism.

Grounded in Fink's (2003) significant learning, which is an adult learning approach, Majeski and Stover (2007:171-185) present strategies for achieving deep learning in online gerontology courses. The study provides strategies for cultivating connections to promote learning and retention in the online classroom. The paper advocates a comprehensive online programme syllabus that encourages interaction and deep learning (Majeski \& Stover, 2007:173-174). This is in addition to presentation areas, class participation, group activities and activities that cultivate connection to influence learning and retention. The paper emphasizes the role of interactive activities in achieving significant learning. In the current research, the theoretical grounding was cognitive constructivism as well as observational learning. In addition, the guidelines arrived at are based on findings of a phenomenological study exploring the lived experiences of facilitators of online learning programmes.

Using a theoretical model based on the Kolb and Lewin learning cycle (Kolb, 1984 in MinasianBatmanian, 2002:645-657) and using a participatory action research, Minasian-Batmanian (2002:645-657) presents guidelines for developing online learning strategies. Her guidelines comprise analysing, designing, developing, testing and evaluating. While making contributions to literature on guidelines for developing online learning strategies, the guidelines are based on the Kolb and Lewin learning cycle (Kolb, 1984 in Minasian-Batmanian, 2002:645-657). In taking the knowledge base further, our current study has a strong pedagogical focus.

According to Moule (2007:37), the most popular process-based online teaching and learning model is that developed by Salmon (2011:26-59). The model consists of five-stages for collaborative online learning from research conducted at the Open University in the United Kingdom, with the underlying assumption that learning involves activities on a computer. She stated further that online learning: “... includes an intricate and complex interaction between neural, cognitive, motivational, affective and social processes ... Learners online move from the known to the unknown."

This work is licensed under a Creative Commons Attribution 4.0 International License. 
In a pedagogical frame, Salmon's five stage model focusses on student engagement and learning online employing constructivist theory. Moule (2007:37-50) on the other hand developed "the elearning ladder" which is based on student interpretations of e-pedagogy reflecting an interpretation of e-learning that encompasses instructivist approaches through to constructivist approaches. The e-learning ladder thus caters for a range of pedagogical approaches. The guidelines proposed in this current study are based on both constructivism and observational learning.

Sultan et al (2011:150), and Dickey (2003:105-121) investigated pedagogically based online learning using different methodologies and samples. Dickey (2003:105-121) reports on a qualitative study of the pedagogical implications of using one 3D virtual world, Active Worlds, for synchronous distance education. The methods employed in this study included participatory observations, class logs and formal and informal interviews with the instructor of a synchronous distance learning course offered through Active Worlds University. The findings of this study were that Active Worlds provides tools that support constructivist learning environments. Dickey's (2003:105-121) research was disseminated in 2003 and formal and informal interviews were conducted with one instructor in 2001. The studies cited above were conducted before 2000, when Web 2.0 technology was in its infancy. Literature has shown that videos are effective online media for facilitating observational learning (Craig et al, 2009:779-789; Charlop et al, 2010:371393; Charlop-Christy et al, 2000:537-552; Geiger et al, 2010:279-383; Nikopoulos \& Keenan, 2003:87-108; Sherer et al, 2001:140-148).

\section{Theoretical Framework}

The theoretical framework in which this study was grounded was constructivism as a learning theory and the functions of observational learning based on social cognitive theory (Bandura 2001:265-299). Hence constructivism is explained, followed by a discussion of Bandura's (2001:273) functions of observational learning.

Baviskar et al (2009:543-544) identify four constructivist criteria and emphasise the need to adhere to the four criteria for any teaching and learning to be considered constructivist. The first critical element is the eliciting of prior knowledge. According to Baviskar et al (2009:544), the creation of cognitive dissonance is the second criterion for the stimulation of constructivist learning. Here the student is made aware of the difference between his or her prior and new knowledge. The third criterion for constructivist learning is the application of the knowledge with feedback. At this stage, the student is required to interpret and modify prior knowledge in the context of new knowledge. Reflection on learning is the fourth criterion for constructivist learning. On integrating the new knowledge permanently, the student ought to become aware that learning has taken place.

This work is licensed under a $\underline{\text { Creative Commons Attribution } 4.0 \text { International License. }}$ 
As a further grounding for the current research, observational learning based on Bandura's (2001:265-299) social cognitive theory was used. Attentional processes during modelling for observational learning determine what is selectively observed in the profusion of modelling influences and what information is extracted from on-going modelling events. Bandura (2001:272) identifies the second major sub-function of modelling for observational learning as retention. Retention involves the active process of transforming and restructuring information conveyed by modelled events into rules and conceptions for memory representation. The third sub-function of modelling for observational learning is the production process. According to Bandura (2001:272), this process involves the translation of symbolic conceptions into appropriate courses of action. The fourth sub-function in modelling for observational learning as identified by Bandura (2001:274) is the motivational process. Social cognitive theory distinguishes between acquisition and performance because people do not always perform everything they learn.

\section{Methodology}

Phenomenology was chosen to study the essences of online learning in an ODL university and the essence of views of academics involved in online facilitation. Although all qualitative research is phenomenological in nature, with the focus on people's experiences, this phenomenological study seeks to understand the essence and structure of online learning in higher education. This study explored the persons in his or her world in online learning in an open and distance learning (ODL) institution.

\section{Population and Sampling}

The population for this research consisted of all facilitators involved in the teaching and learning of online courses at Unisa. The sampling method used was purposive sampling and the sample homogenous, where the participants shared their lived experience of facilitating learning in an online environment. Participants were recruited who shared the experience at the heart of the investigation and did not vary significantly across demographic characteristics (Langdridge, 2007:58). Linear snowball sampling as outlined by Terre Blanche, Durrheim and Painter (2011:139) was used to source information- rich sources. Data collection commenced on receipt of signed informed consent forms from the participants. According to Starks and Trinidad (2007:1375), the size of the sample in phenomenological studies is determined by the number of individuals who can provide detailed accounts of their experience of the phenomenon in order to uncover its core elements. The sample size was thus determined by the attainment of data saturation. The sample for the data collected by means of online interviews consisted of six participants and three participants who were involved in online learning were interviewed face to face.

This work is licensed under a Creative Commons Attribution 4.0 International License. 


\section{Interviews}

All the interviews were conducted by the lead researcher. The interviews were done in two phases. The first phase was done using online semi-structured interviews and the second face-to-face interviews. The data collection in phase one, occurred by means of email allowing for asynchronous communication between the interviewer and the participant and the second phase was done by using face-to-face synchronous communication with additional participants. Prior to conducting the interviews, the researcher presented participants with the permission to conduct research which all participants signed willingly with the assurance that they could withdraw from the research at any time without any penalty. The interviews were conducted over a period of four months. The participants in this research ranged from junior online learning facilitators to full professors. The interviews were tape recorded and transcribed verbatim and checked for accuracy by the second researcher.

\section{Phase one: Online interviews.}

The email allowed participants in the research to write their own lived experiences of online learning, constructivism and observational learning using their own descriptive terms and reflect on their writing prior to submitting their comments online. The researchers choice of online interviews was informed by the benefits it affords the research. In particular, online interviews allowed geographically dispersed participants to participate in the research. The participants were also able to express themselves because the interview did not take the form of a face-to-face focus group where the most vocal or overbearing participant is able to dominate the discussion. In order to overcome possible fears of their comments being freely available on the public internet domain, as in the study conducted by Sharma (2010:132), the researchers secured the question and responses by means of a name and password. The interview question was linked to the functions of observational learning based on social cognitive theory (Bandura, 2001:266) and constructivism (Baviskar, Hartle \& Whitney, 2009: 542-550) and reads as follows: "Would you please give me a written account from your own lived experiences of online learning and the contributions it makes to your teaching?"

\section{Phase two: Face to face interviews.}

All the interviews were conducted by the lead researcher in person at a place convenient for the participants. The interview question was as follows: "Would you please express your experiences of online teaching?"

The researcher used probes related to constructivism and the functions of observational learning where necessary throughout the interview process. She also performed on-going member checking to ensure that she had a clear perspective of the participants' experiences. Snowball sampling continued until data saturation was achieved. Three facilitators were interviewed during this stage. Adequate time was allocated to the interviews and each interview was recorded on a

This work is licensed under a Creative Commons Attribution 4.0 International License. 
data recorder and transferred to the researcher's computer and then transcribed into text in an MsWord document.

At the end of each interview, the participant was thanked and afforded the opportunity to check the transcribed interview and rectify any incorrect transcription. In addition, a second researcher checked the transcriptions for clarity and accuracy. Minimal changes were made on the basis of the second researcher's input.

\section{Data Analysis}

Analysis of the transcribed interviews followed the phenomenological reduction process. The essence of the experience, structure or meaning of online learning for the participants using online learning as teaching tool in ODL, was continually kept in mind during this process. The aim of the data analysis was to study the descriptions of the participants to uncover the essence of the phenomenon of online learning. The meaning of online learning at the university lay in the main themes that the researchers identified in this study through thematic analysis.

The researchers used seven steps to develop situated meaning and structure during data analysis (Merriam, 2002: 124-125). Horizontalisation was used in the process of data analysis as a method to treat the data as equal in weight and value during the initial stage. Data were then clustered into themes and repetitious statements were noted and removed from the final data analysis networks. The final step in the analysis was to construct a synthesis of textual and structural descriptions of online learning in ODL. Throughout the data analysis process, the researchers continually questioned the data and emerging themes noting new descriptions and conceptualisations that were likely to arise. Descriptions of the themes, metaphors and nodes captured the essence of the participants' experiences of online learning and added to the credibility of the study as the themes mirrored the experiences of the phenomenon.

Themes and meanings from each transcript with the assistance of the computer qualitative data analysis program, ATLAS.ti, were identified and categories and subcategories which were related to the research question, were identified. Natural meaning units or phrases which were referred to as quotations from the transcripts were identified and grouped. The themes were central to the transcripts and mirrored the experiences of the participants in this study. The researchers wrote phenomenological comments on each central theme.

Furthermore, concept maps were developed to place the interpretative themes into related fields indicating interconnections around the phenomenon of constructivism and observational learning in an online learning environment by using the computer program, ATLAS.ti. Each transcript and data analysis unit were read and compared by the researcher, the second researcher and the participants for clarity, to ensure consistency of analysis and to implement member checking of information and data analysis.

This work is licensed under a Creative Commons Attribution 4.0 International License. 


\section{Findings of the Phenomenological Exploration}

This section discusses the results under the headings of the five main themes that emerged from the data. Direct quotations from the interviews in italics are provided and indented in the text. References to the quotations from the interviews indicated the participant number and the lines in the transcripts, for example (1:30-35). The text bracketed in italics was added for a better understanding, for example, (when I teach, I use...). In some instances, the researcher added a word or two in square brackets to clarify the meaning, as follows [online learning]:

The five main themes that emerged from the data were as follows:

(1) Theme 1: attention processes with eight nodes

(2) Theme 2: retention processes with ten nodes

(3) Theme 3: production processes as the most comprehensive theme with 12 nodes; this was anticipated because this was the focus of the study and indicated the different media used in online learning

(4) Theme 4: motivational processes with three nodes

(5) Theme 5: current issues in online learning with nine nodes reflecting the issues and problems facilitators experienced when facilitating online learning

It should be noted that sub-themes relating to constructivism were similarly linked to the themes identified above. These original titles for the main themes were changed to more descriptive titles during data analysis to capture the words of the participants. The renamed themes, with examples of the quotations from the participants, are provided in Table 1 below.

\section{Theme 1: Attention processes with eight nodes.}

This theme highlights the processes employed to arouse the students' attention in online learning. The theme described those aspects and processes which the facilitator employed to keep the student interested and engaged in the study material. One participant reflected on how he or she used the prior postings to enforce learning as follows:

When using the discussion forum, I am able to refer to prior postings made and I am also able to refer my students to these prior postings and references made in earlier postings. I have found this to be very helpful to the students learning and my teaching is made easier. (1:12) 


\section{Theme 2: Retention processes with ten nodes.}

Theme 2 on retention processes referred to a great extent to cognitive processes in teaching and learning. This theme was renamed to form a metaphor in order to extrapolate the words of the participants, namely "We need a bridge." The bridge refers to the need for a cognitive process to move from print media to electronic or online learning. This theme consisted of ten nodes which included elements such as a bridge to online learning, knowledge application, teaching assistants, feedback, self-reflection, formative assessment and scaffolding, Participants referred to the bridging processes as follows:

But we need a bridge, we need our students to be online before they register, it's unfair ... I know this is to force them to go online, but it's really, really scary for the students to go online. And I'm going to do a remedial thing for my students from 2014 to try and get them more online from the onset. But we're working on it, we're working on it. (7:22)

\section{Theme 3: Production processes as the most comprehensive theme with 12 nodes; this was anticipated because this was the focus of the study and indicated the different media used in online learning.}

Theme 3 consisted of 11 nodes and was the most comprehensive theme. This was to be expected because the study explored media in online learning. This theme reflected on the production of the learning process and referred to those instruments or tools that facilitators and students use to facilitate learning. The participants commented as follows:

I have found from my experience that discussion forums work best for my teaching. The discussion forum that my students use enables them to view each other's work and this influences them in a positive way. As a result I get a higher quality of assignments than I used to receive before I began using the discussion forum.

\section{Theme 4: Motivational processes with three nodes.}

Theme 4, which dealt with motivational factors and external incentives, was small with only three nodes, namely motivation, social learning and student support. The commitment of the lecturers was evident in the following quote:

Although this is more work for me I still find this very rewarding as the students are the ones who excel and I feel motivated to further assist them. I feel like I know these students even though I have never met them face to face. (1:8)

This work is licensed under a Creative Commons Attribution 4.0 International License. 


\section{Theme 5: Current issues in online learning with nine nodes reflecting the issues and problems facilitators experienced when facilitating online learning.}

Theme 5 related to the challenges that emerged during the study that affected online learning at Unisa. Although the participants in the study were mostly positive and motivated about online learning, the challenges identified in the study were often outside the control of the facilitators and issues relating to systems. The nodes in this theme included elements such as the team approach in curriculum development, support for academics, systems problems, mobile learning, the Digiband (USB wristband), the disadvantages of online learning, resistance to online learning, student dropouts and plagiarism and plagiarism detection tools.

One participant referred to Digiband as follows:

But once again, the digiband is a hindrance to us, which I do not like at all, because we're sitting with copyright issues, because we have links that the copyright ... you know, we can't use them for the digiband, so we have a problem. (7:33)

The disadvantages of online learning referred to the extra workload for academics. One participant stated the following:

The disadvantage I have found with online learning in my course is the additional work I have to do to accommodate both online students and those who do not participate online. It would be ideal if all my students were online and the course was only offered online. This would make the students have to engage. Many experience difficulty with access and I believe many do not yet know how to use the computer effectively. (1:14)

\section{Discussion of the Findings}

Based on the findings of the study, as well as Bandura's (2001:273) observational learning framework, the researchers developed the guidelines for interactive online learning facilitation. The developed guidelines incorporate both constructivist and observational learning criteria, while suggesting activities to counter challenges identified in online learning practice (see Figure 1 below). The developed guidelines comprise the four functions for observational learning (Bandura 2001:272), the four constructivist criteria as explained by Baviskar et al (2009:543-544) and additional themes that emerged from the phenomenological study. The four processes of the functions of observational learning appear in the guidelines. The rest of the guidelines are

This work is licensed under a Creative Commons Attribution 4.0 International License. 
composed of elements that emerged in this research. Current over-riding issues in online learning that impact on the facilitation of online learning are addressed in the guidelines.

The data gathered revealed the need to create an interface between the chair and the keyboard as the first step in online learning. This interface requires an understanding of learning theories amongst the facilitators of online courses. Similarly, an understanding of online learners' skills and competencies is needed so as to provide intervention strategies where necessary. The second step involves the bridge to online learning. The online learning programme sets off with students applying knowledge while receiving support in the form of feedback, formative assessment and scaffolding on a regular basis. The teaching assistants play a key role in this regard. Throughout the online learning processes, a variety of online media are utilised to facilitate learning. This media includes discussion forums, blogs and wikis. The students are kept motivated throughout the process by receiving student support and learning in social contexts.

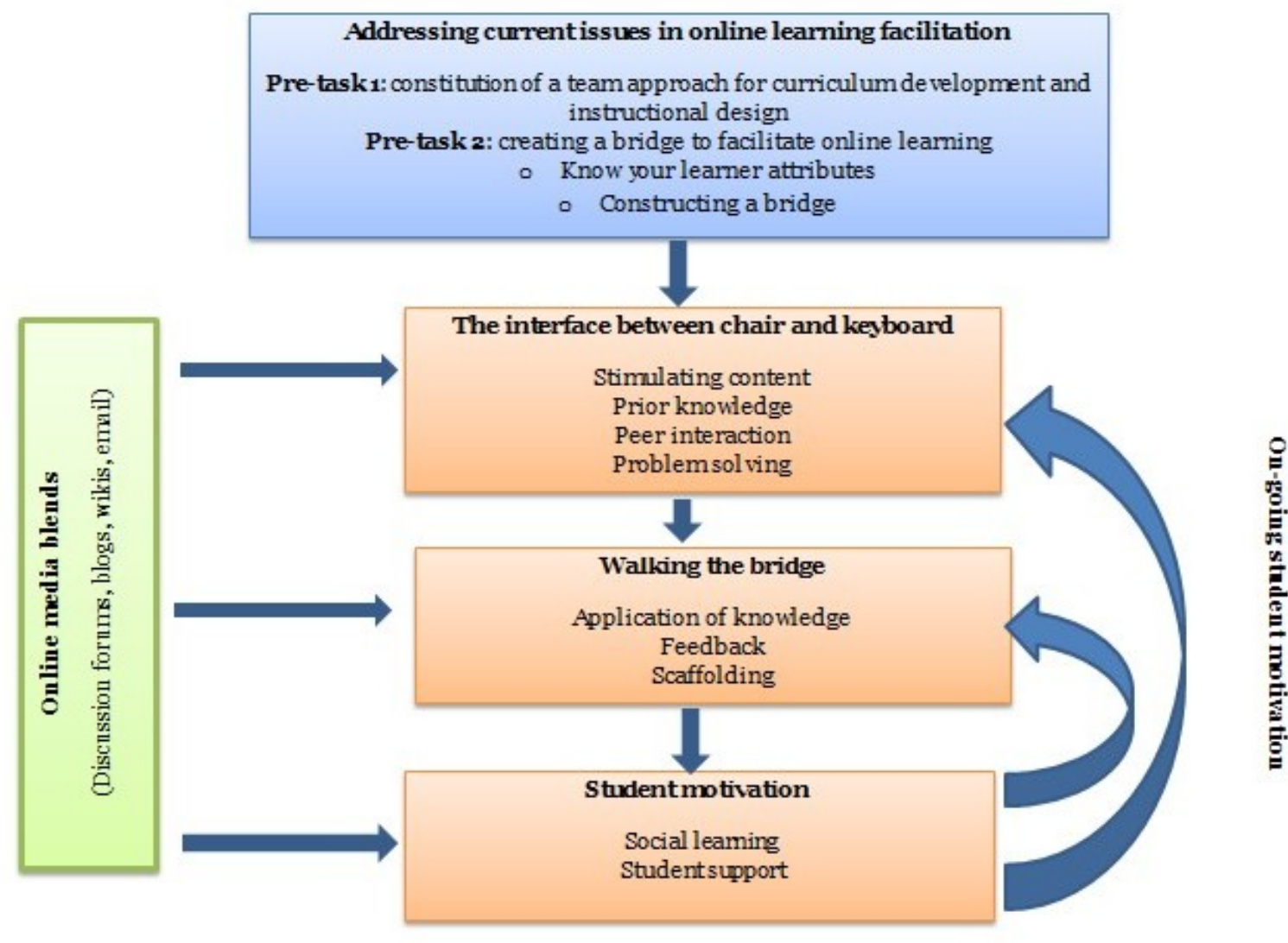

Figure 1. Guidelines for the facilitation of interactive online learning programmes. 
The findings from the phenomenological study indicated that the online media used in online learning environments played a significant role in fostering constructivist and observational learning among students. These findings are consistent with those of Sultan et al (2011:150), and Dickey (2003:105-121) who used different methodologies, samples and online media. Conversely, while literature has shown that videos are effective online media for facilitating observational learning (Craig et al, 2009:779-789; Charlop et al, 2010:371-393; Charlop-Christy, et al 2000:537-552; Geiger et al, 2010:279-383; Nikopoulos \& Keenan, 2003:87-108; Sherer et al, 2001:140-148), the findings of this study revealed that discussion boards and online blogs may help to stimulate observational learning on the part of students.

\section{Recommendations of the Study}

Online learning has grown rapidly in higher and other education in the last decade in many developed and developing countries. South Africa is still developing the skills and technology applications for online learning. In 2013, Unisa embarked on six signature courses, one course per college. Signature courses are introductory courses which introduce students to specific study fields using an online platform. This study included the signature courses at Unisa as well as other courses which use online learning or blended learning approaches such as online learning as well as paper-based approaches.

The findings of this study could inform Unisa's online or technology-enhanced learning practices. The guidelines presented could be used to guide the academic and support staff on the best practices to motivate students and to enhance learning and curb the dropout rates among distance education students. The data suggest that even though social media is available to facilitators in online learning, they do not use it to engage with their students. This information has a direct effect on the way academics plan and teach their students online. Training and support for facilitators in online learning to make use of available media could increase student achievement and encourage students to be more active, motivated and self-aware of their learning and learning needs. Even though there are many new technologies that can be used to enhance learning, most of them are currently outside the control of educational institutions as they lie outside the learning management systems.

Staff involved in online learning need to be properly trained and supported in the pedagogical use of the online media available to them to enhance student learning. More effort should be exercised to promote the role and importance of online tools and applications such as wiki, blog, podcasts and other emerging technologies.

It is further recommended that online learning experience and development at Unisa should be mapped by using phenomenographical research studies. Future research at Unisa in online learning should also include the experiences of students and their specific needs and problems using media blends. The current online courses should be documented by using phenomenographical and action research methodologies for future reference in order to guide

This work is licensed under a Creative Commons Attribution 4.0 International License. 
online learning practice in higher educational institutions that would like to introduce online learning courses.

\section{Conclusion}

The findings of this study extended the work of previous researchers in online learning, observational learning and constructivist learning. This study indicated that the introduction of online learning at universities requires careful pedagogical consideration. This implies that facilitators need to plan activities, interactions and real-life problems which take pedagogy into account while ensuring students stay engaged in their online course. This also implies a shift in the facilitator-student ratio because large numbers of students per facilitator are simply not feasible.

Another conclusion is that staff and students need to have a bridge to move seamlessly from print-based distance education to online learning. This study indicated that the staff needed support in the form of education because most staff members are not familiar with constructivism and observational learning, which are theories behind interactive and engaged learning. Assessment training is needed as online learning moves away from the venue-based examination.

The researchers further concluded that the learning management system, online tools and applications need to be explained and facilitators need more support to use these options. Lastly, social learning and motivational strategies in online learning need to be well planned, as early as at the curriculum development stage. 


\section{References}

Ally, M. (2004). Foundations for educational theory for online learning. In Theory and practice of online learning, edited by $\mathrm{T}$ Anderson \& F Elloumi. http://cde.athabascau.ca/online_book/pdf/TPOL_book.pdf (accessed on 16 March 2012).

Babbie, E. (2008). The basics of social research. $4^{\text {th }}$ edition. Belmont, CA: Thomas Wadsworth.

Baggaley, J . (2014). Online learning: a New Testament. Distance Education 35(1), 133-140.

Bandura, A. (2001). Social cognitive theory of mass communication. Media Psychology 3(3), 265299.

Baviskar, S, Hartle, R.T. \&Whitney, T. (2009). Essential criteria to characterize constructivist teaching: derived from a review of literature and applied to five constructivist-teaching method articles. International J ournal of Science Education 31(4), 542-550.

Blocher, J .M. (2005). Increasing learner interaction: usingJ igsaw online. Educational Media International 42 (3): 269-278.

Chang, S \& Tung, F. (2008). An empirical investigation of students' behavioural intentions to use the online learning course websites. British J ournal of Educational Technology 39(1):7183.

Charlop, M.H., Dennis, B., Carpenter, M.H. \& Greenberg, A.L. (2010). Teaching socially expressive behaviors to children with autism through video modeling. Education and Treatment of Children 33(3):371-393.

Charlop-Christy, M.H., Le, L. \& Freeman, K.A. (2000). A comparison of video modeling with in vivo modeling for teaching children with autism. J ournal of Autism and Developmental Disorders 30:537-552.

Christie, C. \& Garrote J urado R. (2009). Barriers to innovation in online pedagogy. European J ournal of Engineering Education 34(3):273-279.

Clara, M. \& Barbera, E. 2013. Learning online: massive open online courses (MOOCs) connectivism and cultural psychology. Distance Education 34(1):129-136.

Craig, S.D., Chi, M.T.H. \& VanLehn, K. (2009). Improving classroom learning by collaboratively observing human tutoring videos while problem solving. J ournal of Educational Psychology 101(4):779-789.

Dickey, M.D. (2003). Teaching in 3D: pedagogical affordances and constraints of 3D virtual worlds for synchronous distance learning. Distance Education 24(1):105- 121.

Fink, L.D. (2003). Creating significant learning experiences: an integrated approach to designing college courses. San Francisco: J ossey Bass.

This work is licensed under a Creative Commons Attribution 4.0 International License. 
Geiger, K.B., LeBlanc, L.A., Dillon, C.M. \& Bates, S.L. (2010). An evaluation of preference for video and in vivo modeling. J ournal of Applied Behavior Analysis 43:279-383.

Green, N.C., Edwards, H., Wolodko, B., Stewart, C., Brooks, M. \& Littledyke, R. (2010). Reconceptualising higher education pedagogy in online learning. Distance Education 31(3): 257-273.

Koehler, M.J . \& Mishra, P. (2009). What is technological pedagogical content knowledge? Contemporary Issues in Technology and Teacher Education 9(1):60-70.

Langdridge, D. (2007). Phenomenological psychology: theory, research and method. Harlow, UK: Pearson Prentice Hall.

Majeski, R. \& Stover, M. (2007). Theoretically based pedagogical strategies leading to deep learning in asynchronous online gerontology courses. Educational Gerontology 33:171185.

Merriam, S. B. (2002). Qualitative research in practice examples for discussion and data analysis. San Francisco: J ossey-Bass.

Minasian-Batmanian, L. (2002). Guidelines for developing an online learning strategy for your subject. Medical Teacher 24(6):645-657.

Moule, P. (2007). Challenging the five-stage model for e-learning: a new approach. Research in Learning Technology 15(1):37-50.

Nikopoulos, C.K. \& Keenan, M. (2003). Promoting social initiations in children with autism using video modeling. Behavioral Intervention 18:87-108.

Salmon, G. (2011). E-moderating the key to teaching and learning online. $2^{\text {nd }}$ edition. London: Routledge.

Sharma, P. (2010). Enhancing student reflection using weblogs: lessons learned from two implementation studies. Reflective Practice 11(2):127-141.

Sherer, M., Pierce, K.L., Paredes, S., Kisacky, K.L., Ingersoll, B. \& Schreibman, L. (2001). Enhancing conversation skills in children with autism via video technology: which is better, "self" or "other" as model? Behavior Modification 25:140-158.

Slagter van Tryon, P.J . \& Bishop, M.J . (2009). Theoretical foundations for enhancing social connectedness in online learning environments. Distance Education 30 (3): 291-315.

Starks, H. \& Trinidad, S.B. (2007). Choose your method: a comparison of phenomenology, discourse analysis, and grounded theory. Qualitative Health Research 17(10):1372-1380.

So, M.M. (2012). Quality of learning outcomes in an online video-based learning community. Asia-Pacific J ournal of Teacher Education 40 (2):143-158.

Sultan, W.H., Woods, P.C. \& Koo, A-C. (2011). A constructivist approach for digital learning: Malaysian schools case study. Educational Technology and Society 14(4):149-163.

This work is licensed under a Creative Commons Attribution 4.0 International License. 
Terre Blanche, M, Durrheim, K. \&Painter, D. (2011). Research in practice: Applied methods for the social sciences. Cape Town: University of Cape Town Press.

Tuquero, J . (2011). A meta-ethnographic synthesis of support services in distance learning programs. J ournal of Information Technology Education: Innovations in Practice 10:157-179.

(c) Mbati and Minnaar

\section{Athabasca University}

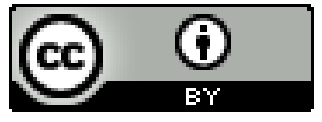

